\title{
Preface to the special issue on the occasion of the 3rd Spain-Italy-Netherlands Meeting on Game Theory (SING 3)
}

\author{
Henk Norde • Fioravante Patrone $\cdot$ Juan Tejada
}

Published online: 4 December 2009

(C) Sociedad de Estadística e Investigación Operativa 2009

From July 4 to 6, 2007, the 3rd Spain-Italy-Netherlands Meeting on Game Theory was held at the Universidad Complutense in Madrid, Spain. The total number of attendants of this meeting was 180, and during the conference approximately 150 papers have been presented in a series of parallel sessions focused on various game theoretical topics. In addition, four plenary lectures were delivered by G. Owen (Strategic Voting in Truth-Tracking Situations), R. Serrano (An Economic Index of Riskiness), K. Sigmund (Voluntary vs compulsory participation in joint enterprises), and W. Thomson (Borrowing-proofness in economies with indivisible goods).

SING 3 is the third meeting in a successful series of meetings on game theory and its applications. The first meeting was held in Maastricht, The Netherlands (2005), the second in Foggia, Italy (2006), the fourth in Wroclaw, Poland (2008), the fifth in Amsterdam, The Netherlands (2009) and this sequence is going to be continued in Palermo, Italy (2010). These meetings are open to all scientists who are interested in any of the aspects of game theory and its applications.

\footnotetext{
H. Norde

CentER and Department of Econometrics and OR, Tilburg University, P.O. Box 90153, 5000 LE Tilburg The Netherlands

e-mail: H.Norde@uvt.nl

F. Patrone $(\varangle)$

DIPTEM, Sezione Metodi e Modelli Matematici, P.le Kennedy, Pad D, 16129 Genova, Italy

e-mail: patrone@diptem.unige.it

J. Tejada

Departamento de Estadística e Investigación Operativa I, Facultad de Matemáticas,

Plaza de Ciencias, 3, Ciudad Universitaria, 28040 Madrid, Spain

e-mail: jtejada@mat.ucm.es
} 
All participants of the SING 3 meeting have been invited to submit their contribution for publication in this special issue. Responsible for the selection procedure have been the undersigned, who acted as guest editors. The standard TOP-refereeing procedure has been applied to any of the submissions and eventually 5 papers have been accepted for publication. 